\title{
Impacto da queima de vegetação do Cerrado sobre fungos habitantes do solo
}

\author{
Impact of burning vegetation on the Cerrado fungi soil \\ Rosângela Ribeiro de Sousa ${ }^{I}$, Evelynne Urzêdo Leão ${ }^{I I}$, Ronice Alves Veloso ${ }^{I I I}$, \\ Marcos Giongo ${ }^{\mathrm{IV}}$, Gil Rodrigues dos Santos ${ }^{\mathrm{V}}$
}

\begin{abstract}
Resumo
Existem poucos estudos relacionados ao impacto de queimadas sobre os fungos habitantes do solo presente no cerrado. Objetivou-se com este trabalho identificar a micoflora presente em amostras de solos, antes e após o processo de queimada em duas profundidades, observando a interferência deste processo na população de fungos habitantes do solo. As amostras foram coletadas em uma área, no município de Jaú do Tocantins, Estado do Tocantins. Foram instalados bioensaios em delineamento experimental inteiramente casualizado, com quatro repetições e cinco tratamentos, representados por diferentes concentrações de solução do solo. A identificação dos fungos foi feita, em nível de gênero, de acordo com suas estruturas morfológicas formadas em meio de cultura, através de observações em microscópio ótico. Na área antes da queimada, observou-se a presença de maior diversidade de gêneros e quantidade de colônias fúngicas. O contrário foi constatado na área posteriormente submetida à queimada, que apresentou menor número de colônias fúngicas. Dos gêneros identificados, destacaram-se Aspergillus, Penicillium, Cladosporium, Fusarium, Mucor, Pythium e Trichoderma, que apresentaram maior número de colônias em quantidades representativas. Observou-se ainda uma redução em torno de $45 \%$ na população de fungos antagonistas. Foi possível constatar que o uso do fogo na vegetação influenciou negativamente as populações microbianas presentes nas camadas mais superficiais do solo de cerrado.
\end{abstract}

Palavras-chave: Microrganismos; Micoflora; Efeito do fogo

\begin{abstract}
There are few studies related to the impact of burnings on soil fungi present in the cerrado. The aim of this work was identify the mycoflora in cerrado soil samples before and after burning process at two depths; observing the interference of this process in the fungi soil inhabitants population. The samples were collected in area, in the municipality of Jaú do Tocantins, State of Tocantins. Bioassays were installed in a completely randomized experimental design, with four replicates and five treatments, represented by different concentrations of soil solution. The identification of the fungi was made at the genus level according to their morphological structures formed in culture medium through optical microscope observations. In the before burning area we observed greatest diversity of genera and fungi colonies. The opposite was found in the area subsequently submitted to the burning process, showing minor fungal colonies. Among the genera identified, Aspergillus, Penicillium, Cladosporium, Fusarium, Mucor, Pythium and Trichoderma were the most representative colonies. We observed a reduction of $45 \%$ approximately in the population of antagonistic fungi. It was found that the use of fire in vegetation negatively influenced microbial populations present in the surface layers of cerrado soil.
\end{abstract}

Keywords: Microorganisms; Mycoflora; Fire effect

Engenheira Agrônoma, MSc., Universidade Federal do Tocantins, Campus Universitário de Gurupi, Rua Badejos, Chácaras 69 e 72, Lt. 07, Sevilha, CEP 77402-970, Gurupi (TO), Brasil. rosangela.sousa20@gmail.com (ORCID: 0000-0002-9564-0291)

Agrônoma, Drª ., Pós-doutoranda (PNPD/CAPES), Universidade Federal do Tocantins, Campus Universitário de Gurupi, Rua Badejos, Chácaras 69 e 72, Lt. 07, Sevilha, CEP 77402-970, Gurupi (TO), Brasil. evelynnegpi@gmail.com (ORCID: 0000-0002-1974-6043)

III Engenheira Agrônoma, Drª̣., Universidade Federal do Tocantins, Campus Universitário de Gurupi, Rua Badejos, Chácaras 69 e 72, Lt. 07, Sevilha, CEP 77402-970, Gurupi (TO), Brasil. ronicealves@hotmail.com (ORCID: 0000-0001-7630-5773)

Engenheiro Florestal, Dr., Professor da Universidade Federal do Tocantins, Campus Universitário de Gurupi, Rua Badejos, Chácaras 69 e 72, Lt. 07, Sevilha, CEP 77402-970, Gurupi (TO), Brasil. giongo@uft.edu.br (ORCID: 0000-0003-1613-6167)

Agrônomo, Dr., Professor da Universidade Federal do Tocantins, Campus Universitário de Gurupi, Rua Badejos, Chácaras 69 e 72, Lt. 07, Sevilha, CEP 77402-970, Gurupi (TO), Brasil. gilrsan@uft.edu.br (ORCID: 0000-0002-3830-9463) 


\section{Introdução}

O cerrado é o segundo maior bioma brasileiro, sendo superado em área apenas pelo bioma Amazônico; ocupa 21\% do território nacional, e é considerado a última fronteira agrícola do planeta (BORLAUG, 2002). O estado do Tocantins localiza-se em uma região de grande importância ecológica, com características singulares, representando uma área de transição entre três dos maiores biomas brasileiros: Amazônico, Cerrado e Caatinga. Segundo Silva (2007), é uma região de forte influência antrópica, com muitas áreas devastadas, necessitando ser mais bem preservada, aumentando-se o percentual de áreas protegidas por unidades de conservação.

Os fungos habitantes do solo constituem uma parte importante da biomassa e têm participação efetiva em diversos processos, tais como: agregação das partículas do solo, decomposição de resíduos orgânicos, mineralização de nutrientes, estabelecimento de relações simbiônticas e controle de pragas e doenças (MONTEIRO, 2012).

Os fungos considerados saprofíticos, juntamente com outros microrganismos, desempenham papel fundamental na formação do solo, evolução da fertilidade, nutrição de plantas, formação e melhoria de sua estrutura, degradação e depuração de substâncias tóxicas (BUÉE et al., 2007). A ciclagem de nutrientes causada por esses microrganismos é de extrema importância na estabilidade e na melhoria do funcionamento dos ecossistemas presentes no solo (PAN et al., 2008). Além de sua importância ambiental, fungos habitantes do solo e seus derivados metabólicos apresentam grande potencial biotecnológico, tais como bioinoculantes para produção agroflorestal, controle biológico, produção de fármacos, entre outros (GOI; SOUZA, 2006).

Por outro lado, o fogo é um dos agentes com maior potencialidade de modificar drasticamente o ambiente e a paisagem, podendo gerar danos irreparáveis à flora e fauna, provocando prejuízos tanto do ponto de vista econômico quanto ambiental (SILVA et al., 2011). Freitas e Sant'Anna (2004), estudando os efeitos das queimadas nos ecossistemas florestais verificaram que a remoção dos detritos do solo, causa uma mudança na disponibilidade de nutrientes, conteúdo de água e pH. Estes autores comentaram que as queimadas provocam a redução no número de organismos, sendo necessários alguns anos para que um novo equilíbrio populacional se estabeleça.

Existem poucos estudos relacionados ao impacto de queimadas sobre os fungos habitantes do solo presente no cerrado. Assim, objetivou-se com o presente trabalho identificar a micoflora presente em solos de cerrado, antes e após o processo de queimada, observando a interferência deste processo na população de fungos habitantes de solo.

\section{Material e métodos}

\section{Coletas de solos}

As amostras foram coletadas em uma área, no município de Jaú do Tocantins, Estado do Tocantins, nas seguintes coordenadas Latitude $12^{\circ} 42^{\prime} 32,4$ " S e Longitude $48^{\circ} 29^{\prime} 23,30^{\prime \prime}$ O. O clima do estado é tropical, a temperatura média é de $32^{\circ} \mathrm{C}$ no período de seca (de abril a setembro) e de $26^{\circ} \mathrm{C}$ no período de chuvas (de outubro a março). Na região sul do estado, as temperaturas médias são cerca de $3^{\circ} \mathrm{C}$ mais baixas do que na região norte, segundo Thornthwaite, no qual o bioma predominante é o cerrado.

Conforme mostra a Figura 1, foram efetuadas duas coletas (antes e após a queima prescrita), em sete transectos amostrais com três pontos de amostragem $(2 \mathrm{~A}, 2 \mathrm{~B}, 2 \mathrm{C}, 4 \mathrm{~A}, 4 \mathrm{~B}, 4 \mathrm{C}, 6 \mathrm{~A}, 6 \mathrm{~B}$, $6 \mathrm{C}, 8 \mathrm{~A}, 8 \mathrm{~B}, 8 \mathrm{C}, 10 \mathrm{~A}, 10 \mathrm{~B}, 10 \mathrm{C}, 12 \mathrm{~A}, 12 \mathrm{~B}, 12 \mathrm{C}, 14 \mathrm{~A}, 14 \mathrm{~B}, 14 \mathrm{C})$, esses pontos foram marcados por GPS. A primeira coleta foi realizada em outubro de 2014, área em condições naturais (presença de árvores de pequeno e médio porte, camada de serrapilheira bem-formada) sem interferência 
do homem e a segunda coleta foi realizada 30 dias após a realização de queima prescrita. $\mathrm{Na}$ área de estudo foram traçadas 15 linhas paralelas equidistantes entre si, em seguida, procederamse as coletas de solo nas profundidades de zero a sete centímetros $(0-7 \mathrm{~cm})$ e abaixo de sete até quatorze centímetros $(7-14 \mathrm{~cm})$, em três pontos distribuídos nas linhas de números pares, como descrito anteriormente (Figura 1).

As amostras de solo foram extraídas com o auxílio de um gabarito $(10 \times 10 \times 10 \mathrm{~cm})$, previamente esterilizado. Cada amostra foi armazenada em sacos plásticos, devidamente identificados e levados ao laboratório. As amostras de solo foram armazenadas sob temperatura ambiente, $28^{\circ} \mathrm{C} \pm 3^{\circ} \mathrm{C}$, no escuro.

Figura 1 - Processo de amostragem realizado em campo

Figure 1 - Sampling process used in the field

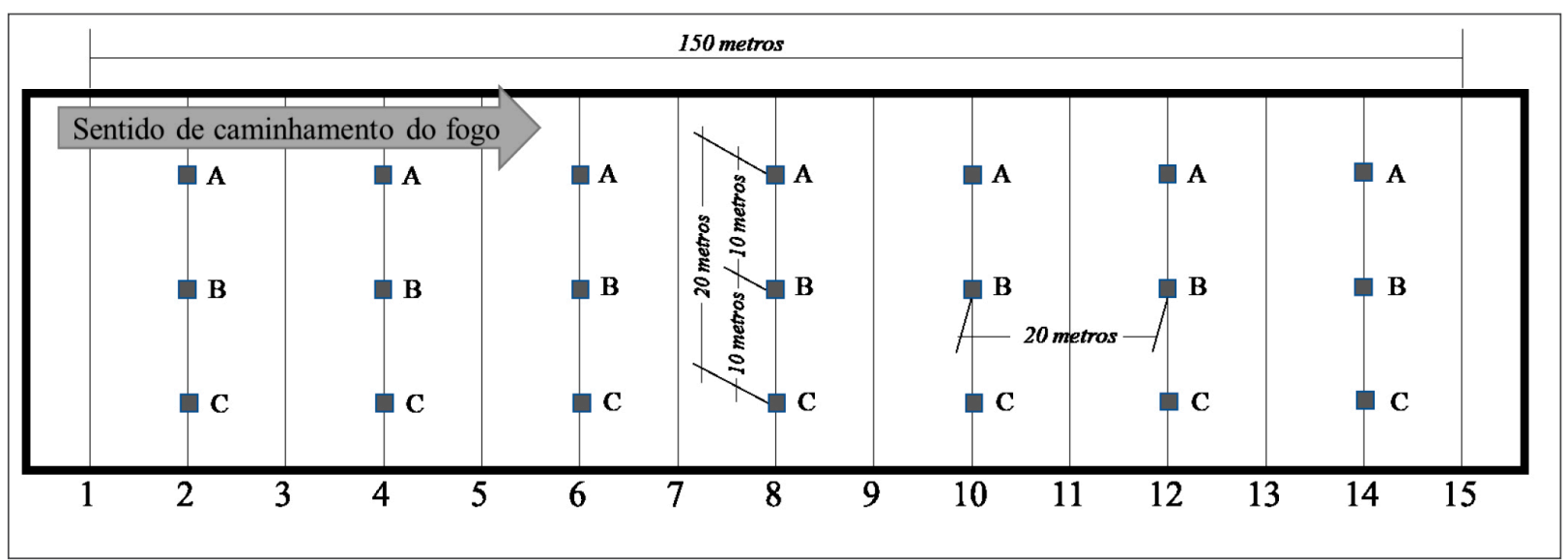

Fonte: autores (2015).

Testes de diluição do solo

Inicialmente, foram realizados testes de diluição de solo buscando-se definir a concentração que melhor expressava a população microbiana. Foram instalados os bioensaios em delineamento experimental inteiramente casualizado, com quatro repetições e cinco tratamentos, os quais foram representados pelas seguintes concentrações de solução do solo: $10^{-2}, 10^{-3}, 10^{-4}, 10^{-5}$ e $10^{-6}$. A partir destas concentrações pipetou-se $1,0 \mathrm{~mL}$ da solução e depositou-se no centro das placas de Petri contendo meio de cultura BDA (batata - dextrose - ágar), no qual foi adicionado o antibiótico Cloranfenicol $50 \mathrm{mg}\left(0,2 \mathrm{~g} \cdot \mathrm{L}^{-}\right)$, proporcionando ao meio seletividade para o desenvolvimento apenas de fungos. A solução foi espalhada na superfície do meio de cultura com o auxílio de uma alça Drigalski. As placas foram lacradas com filme PVC, identificadas e incubadas a $25^{\circ} \mathrm{C} \pm 2^{\circ} \mathrm{C}$ com fotoperíodo de 12 horas, por um período de sete dias. Avaliou-se a quantidade de unidades formadoras de colônias (UFC); essas avaliações começaram a partir do segundo dia, após a incubação das placas, com quatro repetições cada, seguindo metodologia adaptada de Souza (2010).

\section{Quantificação e identificação dos fungos}

Para a quantificação dos fungos presentes no solo foi seguida a metodologia adaptada de Souza (2010). As amostras foram passadas em duas peneiras, sendo inicialmente na malha de 2,00 $\mathrm{mm}$ e, posteriormente, na de $1,00 \mathrm{~mm}$, para separar os torrões e raízes. Em seguida, pesou-se 1,0 g de solo em Becker de $250 \mathrm{~mL}$ com o auxílio de balança analítica e ao solo foi adicionado 99,0 mL 
de água destilada e esterilizada, obtendo-se uma solução estoque de 10 g. $\mathrm{L}^{-2}$. Cada amostra foi homogeneizada por 5 minutos em agitador magnético a $150 \mathrm{rpm}$. Em seguida, adicionou-se a 99,0 $\mathrm{mL}$ de água destilada e esterilizada, $1,0 \mathrm{~mL}$ da solução estoque, obtendo-se uma concentração final de $10^{-3}$. A partir dessa concentração final pipetou-se $1,0 \mathrm{~mL}$ e depositou-se no centro de placas de Petri contendo meio de cultura BDA com antibiótico. A solução foi espalhada na superfície do meio de cultura e as placas foram lacradas, identificadas e incubadas a $25^{\circ} \mathrm{C} \pm 2{ }^{\circ} \mathrm{C}$ com fotoperíodo de 12 horas, por um período de sete dias.

Durante o período de incubação foram contabilizados os números de UFC em cada placa. Utilizou-se o cálculo UFC.g- ${ }^{1}=$ (média das contagens x diluição selecionada x 10) g- $^{1}$. Após os sete dias de incubação procederam-se a identificação e o isolamento dos fungos que colonizavam cada amostra, com o auxílio de um microscópio estereoscópico (lupa) e microscópio ótico. A identificação dos fungos em nível de gênero foi efetuada por observações e comparação de suas estruturas morfológicas, assimilativas e reprodutivas, de acordo com a literatura especializada (BARNETT; HUNTER, 1972; WATANABE, 2002). A identificação em nível de espécie, em alguns casos, foi realizada através de características morfológicas e culturais distintas, como a coloração das colônias e aspecto dos conídios formados em conidióforos.

\section{Resultados e discussão}

\section{Testes de diluição do solo}

Entre as diluições de solos testadas observou-se que as placas com a concentração de $10^{-2}$ de solução do solo (10 g. $\mathrm{L}^{-2}$ ), aos quatro dias de incubação já estavam totalmente colonizadas e sem possibilidade de separação das colônias presentes impossibilitando a identificação dos gêneros. Por outro lado, a partir da concentração de $10^{-4}$ verificou-se que houve uma grande diluição do solo, de modo que se observaram poucas colônias de fungos até os setes dias de incubação, não correspondendo, portanto, à realidade. Por outro lado, a diluição de $10 \mathrm{~g}$ de solo. $\mathrm{L}^{-3}$ proporcionou um número de colônias na superfície do meio, que permitiu a contagem e identificação isolada até os sete dias de incubação, ficando assim determinada a concentração de $10^{-3}$ para a condução do demais ensaios.

\section{Quantificação e identificação de fungos}

Antes da queimada, à profundidade de zero a sete centímetros $(0-7 \mathrm{~cm})$, observou-se a presença de grande número e diversidade de gêneros de fungos nas amostras de solo analisadas (Tabela 1). O contrário foi constatado na área submetida à queimada, apresentando maior número de unidade formadora de colônia fúngica na camada subsuperficial (sete a $14 \mathrm{~cm}$ de profundidade) do que na camada superficial (zero a sete $\mathrm{cm}$ de profundidade). Provavelmente, houve menor temperatura a partir de sete centímetros, possibilitando a maior sobrevivência dos gêneros encontrados. Um fato interessante abordado por Dress e Boerner (2003) refere-se ao solo como um excelente tampão contra a transferência de calor, o que de certa forma favorece os microrganismos que vivem em maiores profundidades. De maneira geral, a temperatura é um fator determinante na distribuição e atividade dos microrganismos do solo, afetando diretamente a fisiologia dos microrganismos e indiretamente exercendo mudanças no ciclo de nutrientes e na atividade da água (LEITE; ARAÚJO, 2007).

Acredita-se que durante o processo de queimada, a camada superficial do solo seja fortemente afetada pelo aumento da temperatura, havendo rápida redução da umidade e destruição dos microrganismos presentes e também da matéria orgânica. Com o passar dos dias deve ocorrer a migração dos fungos sobreviventes das camadas superficiais para as camadas mais profundas. De acordo com Klich (2002), entre outros fatores, a diversidade da comunidade 
fúngica do solo, pode tornar-se reduzida em habitat com baixa diversidade florística, assim, como a realização de queimadas e o manejo de áreas cultivadas podem afetar a diversidade de fungos. Embora os efeitos do fogo sejam atenuados nas camadas inferiores do solo, alguns autores relatam que a fauna edáfica do horizonte orgânico é bastante susceptível a esse processo, por modificar seu habitat (SMITH, 2000). Dessa forma, pode ocorrer uma grande redução do número de indivíduos da fauna do solo após a queima (SILVA et al., 2011). O que pode justificar a menor quantidade de fungos nas camadas superficiais após a queima, pois esta acaba com a camada fértil do solo. Fato este que pode ser comprovado através da análise da população total de fungos, em que houve uma redução de 39,55\%.

Na Tabela 1 estão descritos os números médios de UFC fúngicas identificadas e quantificadas dos diferentes gêneros nas amostras de solos antes e após a queima, em duas profundidades. Foi identificado antes do processo de queima um total de 5.595 UFC nas duas profundidades, e após a queima 3.382 UFC também nas duas profundidades de solo, sendo distribuídos em 14 gêneros distintos, e um gênero não identificado. Dos gêneros identificados, destacaram-se Aspergillus, Penicillium, Cladosporium, Fusarium, Mucor, Pythium e Trichoderma, que apresentaram maior número de colônias em quantidades representativas.

Tabela 1- Número médio de unidades formadoras de colônias (UFC.g ${ }^{-1}$ ) presente em amostras de solos, antes e após o processo de queima, em duas profundidades (0-7 e 7-14 cm), no município de Jaú do Tocantins, 2015

Table 1 - Average number of colony-forming units (CFU.g -1) present in soil samples before and after the firing process, at two depths $(0-7$ and 7-14 cm), in Jaú do Tocantins city, 2015

\begin{tabular}{|c|c|c|c|c|c|c|}
\hline \multirow[b]{2}{*}{ Fungos } & \multicolumn{3}{|c|}{ Antes da Queima } & \multicolumn{3}{|c|}{ Após a Queima } \\
\hline & $0-7^{1}$ & $7-14^{1}$ & Total & $0-7^{1}$ & $7-\mathbf{1 4}^{1}$ & Total \\
\hline Aspergillus niger & 4,02 & 0,70 & 4,72 & 0,49 & 1,50 & 1,99 \\
\hline Aspergillus sp. & 10,73 & 4,86 & 15,59 & 4,24 & 5,74 & 9,98 \\
\hline Colletotrichum sp. & 0,22 & 0 & 0,22 & 0 & 0,11 & 0,11 \\
\hline Cladosporium sp. & 4,35 & 0,96 & 5,31 & 1,59 & 1,86 & 3,45 \\
\hline Curvularia sp. & 0,02 & 2 & 0,04 & 0 & 0,06 & 0,06 \\
\hline Fusarium verticillioides & 0,31 & 0 & 0,31 & 0 & 0,08 & 0,08 \\
\hline Fusarium sp & 8,64 & 1,54 & 10,18 & 2,04 & 4,09 & 5,97 \\
\hline Humicola sp. & 0 & 0,04 & 0,04 & 0 & 0 & 0 \\
\hline Mucor sp. & 1,34 & 0,45 & 1,79 & 0,32 & 0,31 & 0,63 \\
\hline Penicillium sp. & 7,17 & 4,15 & 11,32 & 3,27 & 4,11 & 6,15 \\
\hline Pestalotia sp. & 0,02 & 0 & 0,02 & 0 & 0,02 & 0,02 \\
\hline Pythium sp. & 1,81 & 1,30 & 3,11 & 0,47 & 0,82 & 1,29 \\
\hline Rhizoctonia sp. & 0,35 & 0 & 0,35 & 0,32 & 0,60 & 0,92 \\
\hline Rhizopus sp. & 0 & 0 & 0 & 0 & 0,34 & 0,34 \\
\hline Verticillium sp. & 0,38 & 0 & 0,38 & 0 & 0,08 & 0,08 \\
\hline Trichoderma sp. & 1,17 & 0,79 & 1,96 & 0,33 & 0,74 & 1,07 \\
\hline Não Identificado & 0,16 & 0,45 & 0,61 & 0,02 & 0,27 & 0,29 \\
\hline Total & 40,69 & 15,26 & 55,95 & 13,09 & 20,73 & 33,82 \\
\hline
\end{tabular}

${ }^{1}$ Profundidade do solo em $\mathrm{cm}$. 
A maioria dos gêneros fúngicos identificados neste trabalho são considerados típicos habitantes de solo, sendo a maioria envolvida na decomposição da matéria orgânica. Trabalhos realizados por outros autores confirmam o solo como sendo o habitat característico dos gêneros encontrados no presente trabalho (DOMSCH et al., 2007).

Os fungos do gênero Aspergillus e Penicillium, são causadores de degradação de alimentos, biodeterioração e patogênicos ao homem, animais e plantas. Entretanto, esses microrganismos são muito interessantes, não só em termos de aplicação biotecnológica, mas também para a economia, devido às suas propriedades metabólicas. No contexto da fertilidade do solo, espécies do gênero Aspergillus desempenham importante papel na atividade de formação de nitritos e nitratos. A espécie Aspergillus niger, por exemplo, é considerada um indicador secundários da fertilidade dos solos (MONTALDO, 2010).

Segundo Gomez et al. (2007), a predominância elevada do gênero Penicillium no solo pode estar relacionada ao antagonismo sobre outras espécies, seja por produção de metabólitos secundários ou, mesmo indiretamente, por meio da competição nutricional, da produção elevada de esporos e da maior capacidade de crescimento em meios de cultivo.

O gênero Cladosporium é considerado um colonizador saprofítico primário (DOMSCH et al., 1993), apresentando-se abundantemente distribuído no solo, fazendo parte desta microbiota. Sua população foi diretamente afetada pela a queima, pois houve uma redução de $63,45 \%$ na camada de 0-7 cm, e um aumento de 48,39\% na camada 7-14 cm (Figuras 2 A e B). Fato este que pode estar ligado ao aquecimento da camada superficial, provocando assim a migração dos sobreviventes para as camadas mais profundas, em busca de substrato e consequentemente sobrevivência destes.

Os fungos do gênero Mucor e Rhizopus, encontrados neste estudo, são saprófitos comumente encontrados no solo, em vegetais, frutos, sementes e outros materiais em decomposição (SANTIAGO; MOTTA, 2008). Na população de fungos do gênero Mucor houve uma redução de $64,80 \%$ no total, após a queima da área. Já com relação a do gênero Rhizopus, acredita-se que o mesmo estava presente no solo, antes da queimada, porém, em baixa população de tal modo que não foi detectado na amostragem. Após a queimada, o ambiente pode ter ficado mais propício ao seu desenvolvimento, de modo que sua presença pôde ser constatada.

O gênero Trichoderma é caracterizado por apresentar rápido crescimento de colônias em meios de cultura, sendo comumente encontrado em solos e citado em vários estudos como antagonista de diversos patógenos (DOMSCH et al., 2007). Segundo Baugh et al. (2007), a ação de Trichoderma sp. como estimulador do crescimento é complexa e realizada por interações com fatores bioquímicos e produção de diversas enzimas e compostos benéficos. Há alguns anos, a eficiência desse fungo era discutida, mas sem uso comercial. Entretanto, diversos produtos à base desse antagonista já são comercializados (MICHEREFF; ANDRADE; MENEZES, 2005). O gênero tem potencial antagônico a diversos patógenos habitantes do solo (MELO, 1998).

A queimada da área de estudo promoveu a redução em $45 \%$ da população de Trichoderma sp., comparando-se com a população que havia na mesma área antes da queimada (Figura 2B). Considerado um bom antagonista às espécies de Rhizoctonia sp. e Fusarium sp., que houve um aumento representativo na sua população. Outros fungos foram extintos após a queimada como, por exemplo, os fungos do gênero Humicola.

De maneira geral, os principais efeitos do uso do fogo no solo estão relacionados às alterações biológicas e químicas, tais como redução ou alteração da população microbiana, aumento temporário da disponibilidade de nutrientes, alteração no $\mathrm{pH}$, aumento da fonte de carbono e oxidação da matéria orgânica (SANTOS et al., 1992). Isso contribui para o aumento de fungos mais resistentes e ao mesmo tempo redução da população de fungos que não possuem estruturas de propagação competitiva. 
Figura 2 - Quantificação da porcentagem de redução e aumento do número de unidades formadoras de colônias (UFC. ${ }^{-1}$ ), após o processo de queima, nas profundidades do solo de 0-7 cm (A) e 7-14 cm (B)

Figure 2 - Quantification of the percentage of reduction and increase in number of colonyforming units (CFU.g ${ }^{-1}$ ), after the firing process, the soil depths of $0-7 \mathrm{~cm}(\mathrm{~A})$ and $7-14 \mathrm{~cm}(\mathrm{~B})$

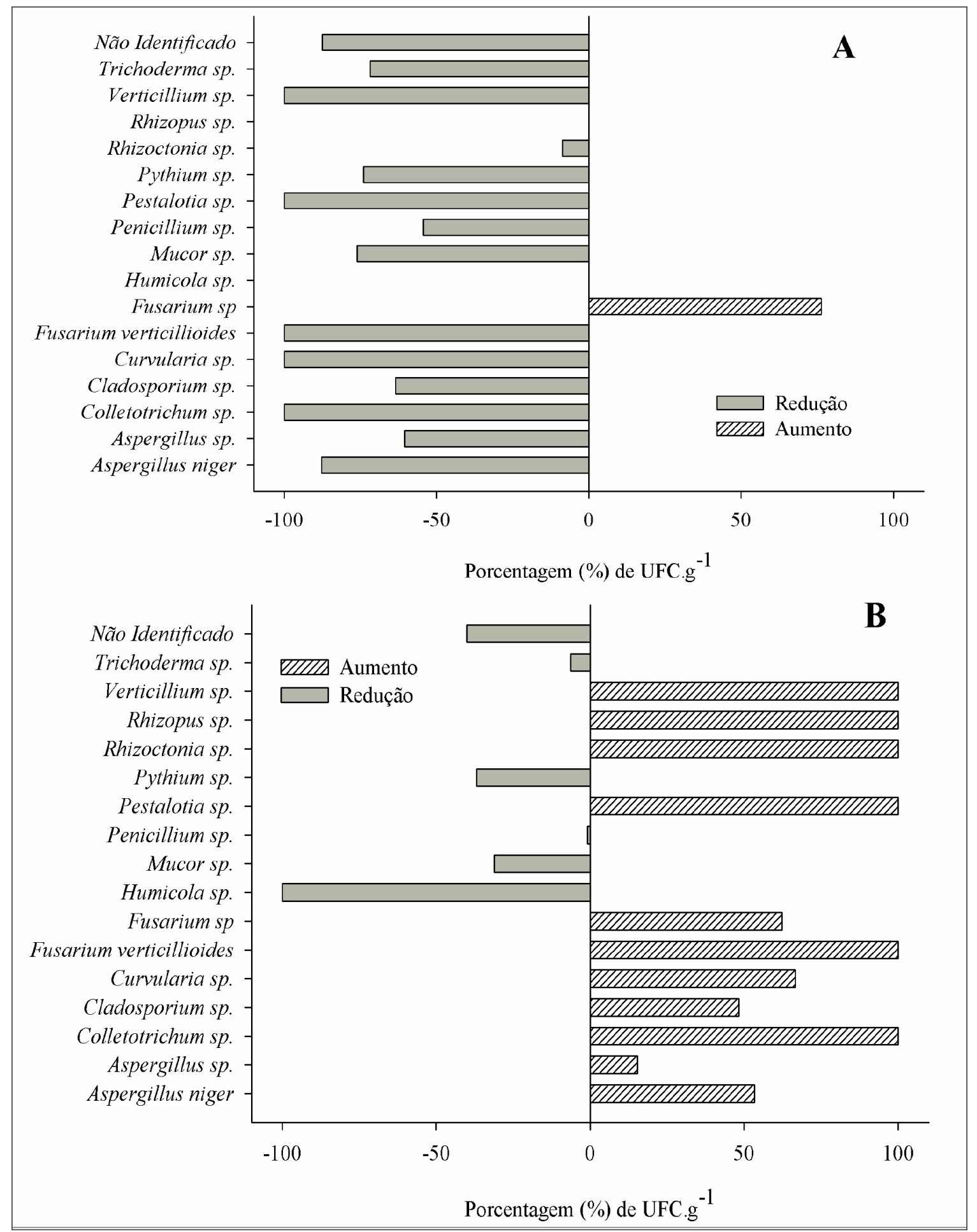

Fonte: autores (2015). 
Costa (2009) relata que com relação aos nutrientes do solo, o fogo pode promover uma redução no teor total, em contrapartida, aumenta a disponibilização destes em virtude da mineralização. Entretanto, quando utilizado em alta intensidade, o fogo pode promover o empobrecimento do solo, uma vez que a combustão nunca é completa e gera além de água, dióxido de carbono e calor. Produz também monóxido de carbono e outros produtos considerados poluentes, como hidrocarbonetos e óxido de nitrogênio (COSTA, 2009). Com isso sabe-se que o fogo exerce ação direta sobre a umidade, matéria orgânica e nutrientes, o que afeta diretamente a população fúngica.

Um efeito direto do fogo sobre o solo é a elevação da temperatura, que, segundo Schacht et al. (1996), pode promover o aumento na taxa de decomposição dos resíduos e na taxa de mineralização da matéria orgânica. Soares (1995) relata que o empobrecimento do solo através do fogo pode ocorrer basicamente em duas situações, primeiro, em incêndios de alta intensidade, que queimam, volatilizam ou dispersam quase toda a matéria orgânica e a maior parte dos nutrientes; e segundo modo em que ocorre o empobrecimento do solo é quando este sofre queimas sucessivas e com isso o capital de nutrientes do solo é reduzido gradualmente.

O levantamento de fungos de solo tem sido eficaz para ampliar o conhecimento sobre a diversidade desses microrganismos, permitindo que novas espécies sejam identificadas e novos registros sejam realizados, o que abre a possibilidade de sua posterior utilização em diversos fins (MARQUES et al., 2008). Através do presente trabalho, ficou evidente que o fogo causa alterações de grande impacto nas populações de fungos habitantes do solo; e, provavelmente, de outros microrganismos presentes no solo, envolvidos em processos de transformações da matéria orgânica, mineralizações, bem como produção de metabólitos do solo. Desta forma, acredita-se que o uso da queimada, mesmo de forma controlada, afeta significativamente a sobrevivência das populações microbianas habitantes do solo, bem como pode influenciar negativamente na dinâmica do ecossistema presente no cerrado.

\section{Conclusões}

Os resultados obtidos demonstram a elevada diversidade de fungos presentes no solo de cerrado, representando contribuição relevante para o conhecimento da microbiota desse bioma e subsídios para a sua conservação.

Os gêneros de maior incidência no solo estudado foram Aspergillus, Penicillium, Cladosporium, Fusarium, Mucor, Pythium e Trichoderma, que apresentaram maior número de colônias.

Observou-se que a partir do processo de queimada da vegetação do cerrado, considerando até o período de 30 dias após, de um modo geral, diminuiu o número de microrganismos do solo nas camadas mais superficiais, representando uma medida inadequada de manejo.

\section{Referências}

BARNETT, H. C.; HUNTER, B. B. Illustrated genera of imperfect fungi. 3th ed. Mineapolis: Burgess Publishing, 1972. 241 p.

BAUGH, C. L. et al. The genus bacillus and genus Trichoderma for Agricultural bioaugmentation. [S.l.: s.n.], 2007. 4 p.

BORLAUG, N. E. Feeding a world of 10 billion people: the miracle ahead. In: BAILEY, R. (Ed.). Global warming and other eco-myths. Roseville: Competitive Enterprise Institute, 2002. p. 2960 .

BUÉE, M. et al. Soil niche effect on species diversity and catabolic activities in an ectomycorrhizal fungal community. Fems Microbiology Ecology, Amsterdam, v. 39, n. 8, p. 1947-1955, 2007. 
COSTA, M. R. G. F. Uso do fogo em pastagens naturais. Fortaleza: Universidade Federal do Ceará, 2009. 24 p.

DOMSCH, K. H. et al. Compendium of soil fungi. 2nd ed. Eching: IHW-Verlag, 1993. v. 1.

DOMSCH, K. H. et al. Compendium of soil fungi. London: Academic, 2007. 672 p.

DRESS, J. D.; BOERNER, E. J. Patterns of microarthropod abundance in oak-hickory forest ecosystems in relation to prescribed fire and landscape position. Pedobiologia, Jena, v. 47, n. 1, p. 1-8, 2003.

FREITAS, L. C.; SANT'ANNA G. L. Efeito do fogo nos ecossistemas florestais. Revista da Madeira, Curitiba, v. 14, n. 79, 2004.

GOI, S. R.; SOUZA, F. A. Diversidade de microrganismos do solo. Floresta e Ambiente, Seropédica, v. 13, n. 2, p. 46-65, 2006.

GOMEZ, E. et al. Fungal abundance and distribution as influenced by clearing and land use in vertc soil of Argentina. Biology and Fertility of Soils, Berlin, v. 43, n. 3, p. 373-377, 2007.

KLICH, M. A. Biogeography of Aspergillus species in soil and litter. Mycologia, New York, v. 94, n. 1, p. 21-27, 2002.

LEITE, L. F. C.; ARAÚJO, A. S. F. Ecologia microbiana do solo. [S.1.]: EMBRAPA Meio-Norte, 2007. 24 p.

MARQUES, M. F. O. et al. Riqueza de espécies de fungos conidiais em duas áreas de Mata Atlântica no morro da pioneira, Serra da Jibóia, BA, Brasil. Acta Botânica Brasilica, Porto Alegre, v. 22, n. 4, p. 954-961, 2008.

MICHEREFF, S. J.; ANDRADE, D. E. G. T.; MENEZES, M. Ecologia e Manejo de patógenos radiculares em solos tropicais. Recife: Imprensa Universitária, 2005. 398 p.

MELO, I. S. Agentes microbianos de controle de fungos fitopatogênicos. In: MELO, I. S.; AZEVEDO, J. L. (Ed.). Controle Biológico. Jaguariúna: EMBRAPA Meio Ambiente, 1998. v. 1. p. 17-67.

MONTALDO, J. C. Respiração e densidade microbiana em solo cultivado com cana-deaçúcar submetido a diferentes sistemas de colheita. 2010. $43 \mathrm{f}$. Trabalho de conclusão de curso (Agronomia) - Universidade Federal de Alagoas, Maceió, 2010.

MONTEIRO, M. C. P. Identificação de fungos dos gêneros Aspergillus e Penicillium em solos preservados do cerrado. 2012. 77 f. Dissertação (mestrado em Microbiologia Agrícola) Universidade Federal de Lavras, Lavras, 2012.

PAN, H. et al. Diversity analysis of soil dematiaceous hyphomycetes from the Yellow River source area. Journal of Zehejiang University Science B, Hangzhou, v. 9, n. 10, p. 829-834, 2008.

SANTIAGO, A. L. C. M. A.; MOTTA, C. M. S. Isolation of Mucorales from processed maize (Zea mays L.) and screening for protease activity. Brazilian Journal of Microbiology, São Paulo, v. 39, n. 4, p. 698-700, 2008.

SANTOS, D. et al. Queimadas e erosão do solo. Informe Agropecuário, Belo Horizonte, v. 16, n. 176, p. 62-68, 1992.

SCHACHT, W. H. et al. Soil quality response of reestablished grasslands to mowing and burning. Journal of Range Management, Litletton, v. 49, n. 5, p. 458-463, 1996.

SOARES, R. V. Prevenção e Combate a Incêndios Florestais. In: FÓRUM NACIONAL SOBRE INCÊNDIOS FLORESTAIS, 1.; REUNIÃO CONJUNTA IPEF-FUPEF-SIF, 3. Anais... [S.l.: s.n.], 1995. p. 6-10. 
SILVA, L. A. G. C. Biomas presentes no estado do Tocantins. Nota Técnica Câmara dos deputados. Brasília: Câmara dos Deputados, 2007. 10 p.

SILVA, R. F. et al. Impacto do fogo na comunidade da fauna edáfica em florestas de Eucaliptus grandis e Pinus taeda. Revista Brasileira de Agrociência, Pelotas, v. 17, n. 2-4, p. 234-241, 2011.

SMITH, J. K. Wild land fire in ecosystems: effects of fire on fauna. General Technical Report RMRS-GTR-42- v.1. Ogden: U.S. Department of Agriculture, Forest Service, Rocky Mountain Research Station, 2000. 83 p.

SOUZA, C. N. Diversidade de fungos do solo da Mata Atlântica. 2010. 67 f. Dissertação (Mestrado em Microbiologia Agrícola) - Universidade Federal de Lavras, Lavras, 2010.

WATANABE, T. Pictorial atlas of soil and seed fungi: morphologies of cultured fungi and key to species. 2nd ed. [S.1.]: CRC Press, 2002. 486 p. 